\title{
Isolated limb perfusion with actinomycin D and TNF-alpha results in improved tumour response in soft-tissue sarcoma-bearing rats but is accompanied by severe local toxicity
}

\author{
ALB Seynhaeve', JHW de Wilt', ST van Tiel', AMM Eggermont' and TLM ten Hagen*,' \\ 'Department of Surgical Oncology, University Hospital Rotterdam Dijkzigt/Daniel den Hoed Cancer Center, Rotterdam, the Netherlands
}

Previously we demonstrated that addition of Tumour Necrosis Factor- $\alpha$ to melphalan or doxorubicin in a so-called isolated limb perfusion results in synergistic antitumour responses of sarcomas in both animal models and patients. Yet, 20 to $30 \%$ of the treated tumours do not respond. Therefore agents that synergise with tumour necrosis factor alpha must be investigated. Actinomycin $D$ is used in combination with melphalan in isolated limb perfusion in the treatment of patients with melanoma in-transit metastases and is well known to augment tumour cell sensitivity towards tumour necrosis factor alpha in vitro. Both agents are very toxic, which limits their systemic use. Their applicability may therefore be tested in the isolated limb perfusion setting, by which the tumours can be exposed to high concentrations in the absence of systemic exposure. To study the beneficial effect of the combination in vivo, BN- 175 soft tissue sarcoma-bearing rats were perfused with various concentrations of actinomycin $D$ and tumour necrosis factor alpha. When used alone the drugs had only little effect on the tumour. Only when actinomycin D and tumour necrosis factor alpha were combined a tumour response was achieved. However, these responses were accompanied by severe, dose limiting, local toxicity such as destruction of the muscle tissue and massive oedema. Our results show that isolated limb perfusion with actinomycin D in combination with tumour necrosis factor alpha leads to a synergistic anti-tumour response but also to idiosyncratic locoregional toxicity to the normal tissues. Actinomycin D, in combination with tumour necrosis factor alpha, should not be explored in the clinical setting because of this. The standard approach in the clinic remains isolated limb perfusion with tumour necrosis factor alpha in combination with melphalan. British Journal of Cancer (2002) 86, II74-I I79. DOl: I0.1038/sj/bjc/6600 I69 www.bjcancer.com (c) 2002 Cancer Research UK

Keywords: tumour necrosis factor alpha; actinomycin D; isolated limb perfusion; rats

In 1958 Creech et al (1958) described the application of an isolated limb perfusion (ILP) for the treatment of a patient with a melanoma in-transit metastases who refused amputation. Perfusions with melphalan in these patients results in fairly good response rates in contrast to patients with locally advanced extremity soft tissue sarcomas (STS) (Eggermont, 1996a). The addition of tumour necrosis factor-alpha (TNF) has dramatically changed the efficacy of the procedure in patients with extremity STS. Eggermont et al $(1996 b, c)$ reported that in patients with advanced STS an ILP with $\mathrm{TNF}+$ melphalan with Interferon-gamma or without interferongamma improved tumour response rates to above $80 \%$ resulting in a limb salvage in over $70 \%$ of the patients destined otherwise to undergo an amputation. The results of the multicenter studies in Europe eventually lead to the approval of TNF for this indication in Europe (Eggermont et al, 1999). Despite these good results, still 20 to $30 \%$ of these patients do not respond to this therapy and other agents that can further improve this treatment must be identified.

*Correspondence: Dr TLM ten Hagen; Department of Surgical Oncology, Erasmus University Rotterdam, Dr. Molewaterplein 50, 30 I5 GE Rotterdam, the Netherlands; E-mail: tenhagen@heel.fgg.eur.nl

Received 24 August 200 I; revised I8 December 200 I; accepted 7 January 2002
In rat osteo- and soft tissue sarcoma ILP models we were able to mimic the clinical ILP with comparable response type and rate (Manusama et al, 1996). In this setting new drug combinations can be tested rapidly. To improve response rates doxorubicin has been used instead of melphalan. However, ILP with doxorubicin in combination with TNF appeared less effective than melphalan with TNF. Response rates were respectively 54 and 70\% (de Wilt et al, 1999; Van Der Veen et al, 2000).

Actinomycin D is an anticancer antibiotic that has been used in combination with melphalan in the ILP setting in the treatment of patients with melanoma in-transit metastases confined to the extremities. It is an interesting drug to evaluate in combination with TNF because incubation of tumour cells with actinomycin D has been shown to increase their sensitivity to the effects of TNF (Alexander et al, 1987). Administration of TNF and actinomycin D in mice delayed the growth of several tumours significantly, but application was limited due to the severe toxic effects (Mosende et al, 1977). Patients with osteogenic sarcoma have been treated with actinomycin D in combination with bleomycin and cyclophosphamide. This treatment was associated with severe nausea and anorexia (Lasek et al, 1996). With an ILP a high drug concentration can be administered with minimal systemic toxicity due to negligible leakage to the rest of the body (Lienard et al, 1992). In this way, melphalan has been used for many years as a single drug treatment with a local concentration 15-20 times higher than can be achieved by systemic treatment (Benckhuijsen et al, 1988). 
In the presented study we performed ILP with the combination of actinomycin D and TNF to study their potential of inducing a tumour response. In vitro studies were undertaken to examine the direct effect of the agents on tumour cells.

\section{MATERIALS AND METHODS}

\section{Animals}

Male inbred BN rats, weighing 250-300 g, obtained from HarlanCPB (Austerlitz, the Netherlands) were used for isolated limb perfusions. Rats were fed a standard laboratory diet ad libitum (Hope Farms Woerden, the Netherlands) and were housed under standard conditions. The experimental protocols adhered to the rules outlined in the 'Dutch Animal Experimentation Act' (1977) and the published 'Guidelines of the UKCCCR for the welfare of animals in experimental Neoplasia' (UKCCCR, 1998). The protocol was approved by the committee on Animal Research of the Erasmus University Rotterdam, the Netherlands.

\section{Tumour model}

The rapidly growing and metastasising $\mathrm{BN}-175$ soft tissue sarcoma, which is transplantable to the $\mathrm{BN}$ rat, was used. Fragments of $2-$ $3 \mathrm{~mm}$ were implanted subcutaneously in the right hind limb, just above the ankle. Perfusion was performed at a tumour diameter of $13 \pm 2 \mathrm{~mm}$, approximately 7 days after implantation. Tumour growth was recorded by calliper measurements and the volume was calculated with the formula $0.4\left(\mathrm{~A}^{2} \times \mathrm{B}\right)$, where $\mathrm{B}$ stands for the largest diameter of the tumour and $\mathrm{A}$ the diameter perpendicular to B.

\section{Drugs}

Recombinant human TNF (rHuTNF) was provided by Boehringer (Boehringer Ingelheim $\mathrm{GmbH}$, Austria) with a specific activity of $5.8 \times 10^{7} \mathrm{U} \mathrm{mg}^{-1}$ as determined in the murine L-M cell assay. Endotoxin levels were $<1.25$ units (EU) per mg protein. TNF concentrations used were $50 \mu \mathrm{g}$ in $5 \mathrm{ml}$ perfusate.

Actinomycin D (Sigma, the Netherlands) was diluted in phosphate buffered saline to a concentration of $2 \mathrm{mg} \mathrm{ml}^{-1}$. Concentrations used were 5 and $10 \mu \mathrm{g}$ in $5 \mathrm{ml}$ perfusate.

Melphalan (Alkeran, Wellcome, Beckenham, UK) was diluted in phosphate buffered saline to a concentration of $2 \mathrm{mg} \mathrm{ml}^{-1}$. Concentrations used were $40 \mu \mathrm{g}$ in $5 \mathrm{ml}$ perfusate.

\section{In vitro assessment of anti-tumour activity}

Cells isolated from a BN-175 soft tissue sarcoma were maintained in cell culture for a maximum of 20 passages in RPMI supplemented with $10 \%$ foetal bovine serum and L-glutamine. Media and supplements were obtained from Life Technologies, the Netherlands.

BN soft tissue sarcoma cells were added in $100 \mu \mathrm{l}$ aliquots to 96well plates at a final concentration of $10^{4}$ cells per well and allowed to grow as a monolayer. Actinomycin D and rHuTNF, diluted in RPMI supplement with $10 \%$ foetal bovine serum and L-glutamine, were added to the wells and allowed to incubate for 3 days. The range of final drug concentration in the well was 0.05$100 \mathrm{ng} \mathrm{ml}^{-1}$ for actinomycin $\mathrm{D}$ and $0-10000 \mathrm{ng} \mathrm{ml}^{-1}$ for rHuTNF. As a control the TNF sensitive cell line WEHI-164 was used. The cells were incubated in the presence of a concentration of $0.05-100 \mathrm{ng} \mathrm{ml}^{-1}$ actinomycin $\mathrm{D}$ and $0-1 \mathrm{ng} \mathrm{ml}^{-1} \mathrm{TNF}$, diluted in RPMI supplement with $10 \%$ foetal bovine serum and L-glutamine. The sulphorhodamine B (SRB) protein stain assay was used according to the method of Skehan et al (1990). Briefly, cells were washed with phosphate buffered saline (PBS), incubated with $10 \%$ trichloric acetic acid in distilled water $\left(1 \mathrm{~h}, 4^{\circ} \mathrm{C}\right)$ and washed again in distilled water. Cells were then stained for 15 to 30 min with SRB (Sigma, St. Louis, MO, USA), washed with $1 \%$ acetic acid in distilled water and allowed to dry. Protein bound SRB was dissolved in $10 \mathrm{~mm}$ Tris buffer, pH 9.4 and absorption was measured at $540 \mathrm{~nm}$. Tumour growth was calculated using the formula: percentage tumour growth=(test well/control well) $\times 100 \%$.

\section{Isolated Limb Perfusion (ILP) model}

The perfusion technique was performed as described previously (de Wilt et al, 1999). Briefly, animals were anaesthetised with Ketalin (Apharmo, Duiven, the Netherlands) and Xylazin (Bayer B.V., Mijdrecht, the Netherlands). To prevent coagulation 50 IU of heparin was injected intravenously. To keep the rat's hind limb at a constant temperature of $38-39^{\circ} \mathrm{C}$, a warm water mattress was applied. Temperature was measured with a temperature probe on the skin covering the tumour. The femoral artery and vein were cannulated with silastic tubing ( 0.012 in inner diameter (ID), 0.025 in outer diameter (OD); 0.025 in ID, 0.047 in OD respectively, Dow Corning, MI, USA). Collaterals were occluded by a groin tourniquet, and isolation time started when the tourniquet was tightened. An oxygenation reservoir and a roller pump were included into the circuit. The perfusion solution was $5 \mathrm{ml}$ Haemaccel (Behring Pharma, Amsterdam, the Netherlands). The cytotoxic drugs with or without TNF were added as boluses to the oxygenation reservoir. A roller pump (Watson Marlow, Falmouth, UK; type $505 \mathrm{U}$ ) recirculated the perfusate at a flow rate of $2.4 \mathrm{ml} \mathrm{min}^{-1}$. A washout with $5 \mathrm{ml}$ oxygenated Haemaccel was performed at the end of the perfusion.

Tumour growth was daily recorded by calliper measurement. Tumour volume was calculated as $0.4\left(\mathrm{~A}^{2} \mathrm{~B}\right)$, where $\mathrm{B}$ represents the longest diameter and $\mathrm{A}$ the diameter perpendicular to $\mathrm{B}$.

\section{Assessment of limb function}

Limb function was a clinical observation in which the rat's ability to walk and stand on the perfused limb was scored 1 day after ILP and is an identification for the toxicity of the used chemicals. On this scale a severe impaired function (grade 0) means that the rat drags its hind limb without any function; a slightly impaired function (grade 1) means the rat does not use its hind limb in a usual matter, but stands on it when rising; an intact function of the hind limb (grade 2) means a normal walking pattern.

Oedema was scored as no formation of oedema $(-)$, or oedema resulting in leg diameter increase of 1.5 -fold or more $(+)$.

\section{Histology}

The day after perfusion with actinomycin $\mathrm{D}$ alone or in combination with TNF tumour and muscle tissue of the perfused limb was removed fixed for $24 \mathrm{~h}$ in $4 \%$ formaldehyde and embedded in paraffin. Muscle from the non-perfused limb was also obtained, fixed and embedded. Tissue sections of $4 \mu \mathrm{m}$ were cut and stained with haematoxylin and eosin, followed by examination using a Leica DM-RXA.

\section{Statistical analysis}

Mann-Whitney $U$-test was used to compare tumour volumes. Calculations were performed on a personal computer using GraphPad Prism v3.0 and SPSS v8.0 for Windows 98.

\section{RESULTS}

\section{In vitro assessment of anti-tumour activity}

Previously, we demonstrated the lack of synergy between melphalan and TNF in vitro (Manusama et al, 1996). To investigate the effect of 
actinomycin D and TNF directly on the $\mathrm{BN}-175$ tumour cells a bioassay was performed. Exposure of the BN-175 sarcoma cells to actinomycin $\mathrm{D}$ resulted in a dose related cytotoxicity with an $\mathrm{IC}_{50}$ of $1 \mathrm{ng} \mathrm{ml}-1$ (Figure 1A). When used alone TNF had no cytotoxic or cytostatic effect on this tumour cell line. Addition of TNF to actinomycin D did not alter the $\mathrm{IC}_{50}$ of actinomycin $\mathrm{D}$, indicating lack of any synergy between the two drugs on this cell line. Incubation of the TNF sensitive cell line WEHI-164 resulted in synergy when the cells were treated with a combination actinomycin D and TNF (Figure 1B).

\section{In vivo tumour response to actinomycin $\mathrm{D}$ and $\mathrm{TNF}$ after ILP}

We evaluated the anti-tumour effect of actinomycin D and melphalan with or without TNF after an isolated limb perfusion.
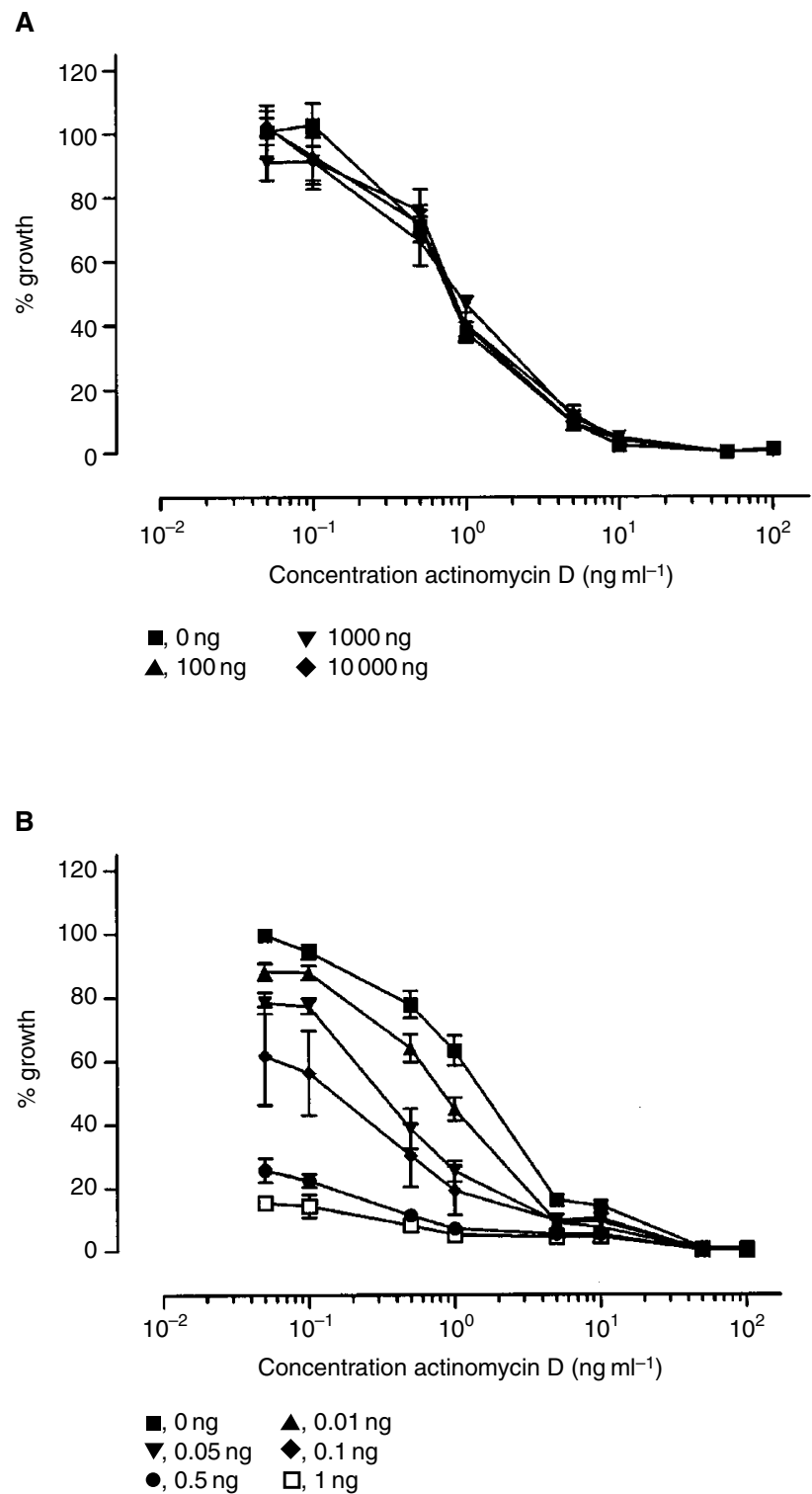

Figure I In vitro growth of $\mathrm{BN}-175$ sarcoma cells $(\mathbf{A})$ as a function of the actinomycin D concentration in combination with $0 \mathrm{ng}, 100 \mathrm{ng}, 1000 \mathrm{ng}$ and $10000 \mathrm{ng}$ TNF per $\mathrm{ml}$. The mean of seven individual experiments performed in duplicate are shown ( \pm s.e.m.). And the in vitro growth of WEHII 64 murine cells $(\mathbf{B})$ as a function of the actinomycin D concentration in combination with $0 \mathrm{ng}, 0.01 \mathrm{ng}, 0.05 \mathrm{ng}, 0.1 \mathrm{ng}, 0.5 \mathrm{ng}$ and I ng TNF per $\mathrm{ml}$. The mean of seven individual experiments performed in duplicate are shown ( \pm s.e.m. $)$
BN-175 soft tissue sarcoma-bearing rats were perfused with different concentrations of actinomycin D or melphalan with or without TNF.

Perfusions with Haemaccel (sham), or with $50 \mu \mathrm{g}$ TNF or $5 \mu \mathrm{g}$ actinomycin $\mathrm{D}$ alone, resulted in progressive disease in all animals (Figure 2A). Addition of $50 \mu \mathrm{g}$ TNF to ILP with $5 \mu \mathrm{g}$ actinomycin $\mathrm{D}$ not only resulted in inhibition of the tumour growth, but also in tumour shrinkage. At 5 days after ILP a significant difference in the mean tumour volume was observed as compared to sham perfusions $(P<0.05)$, TNF perfusions alone $(P<0.05)$ and actinomycin $\mathrm{D}$ perfusions alone $(P<0.05)$. The perfusions with a combination of $5 \mu \mathrm{g}$ actinomycin D and $50 \mu \mathrm{g}$ TNF resulted in a response rate of $40 \%$ (data not shown). When perfusions were performed with a higher concentration of actinomycin D a further increase in tumour response was observed. However due to the severe toxicity with this concentration no further experiments were performed. Perfusions with $40 \mu \mathrm{g}$ melphalan and $50 \mu \mathrm{g}$ TNF resulted also in major tumour shrinkage. A significant difference was observed as compared to sham perfusions, TNF perfusions alone and melphalan perfusions alone $(P<0.05)$ (Figure $2 \mathrm{~B}$ ). Perfusions with $40 \mu \mathrm{g}$ melphalan and $50 \mu \mathrm{g}$ TNF resulted in a

A

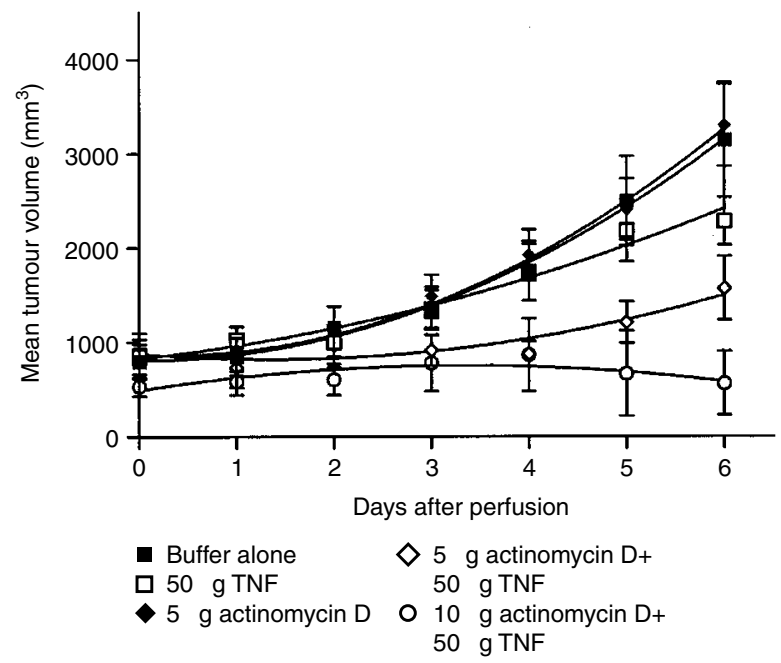

B

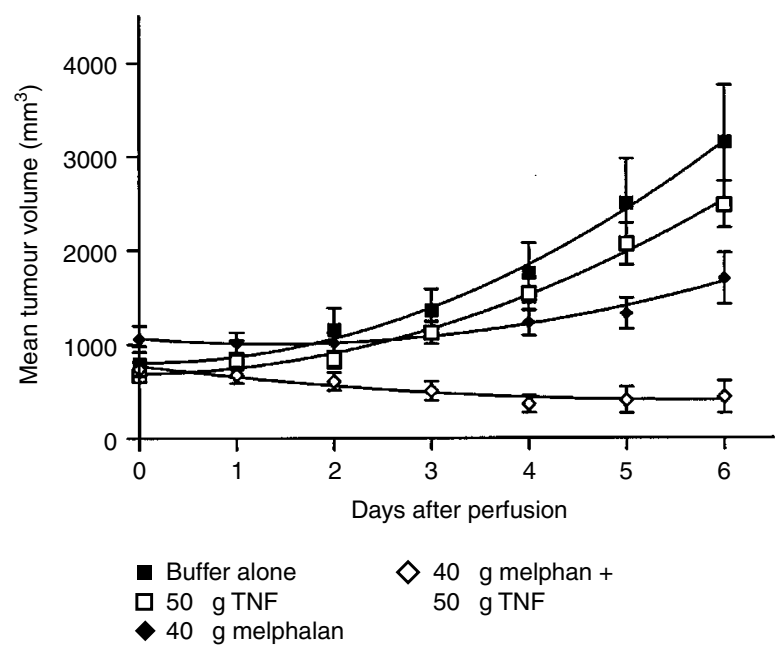

Figure 2 Growth curves of subcutaneous implanted BN- 175 sarcoma (A) after isolated limb perfusion with buffer alone, $50 \mu \mathrm{g}$ TNF, $5 \mu \mathrm{g}$ actinomycin D, $5 \mu \mathrm{g}$ actinomycin D combined with $50 \mu \mathrm{g}$ TNF and $10 \mu \mathrm{g}$ actinomycin D combined with $50 \mu \mathrm{g} T \mathrm{TF}$ and $(\mathbf{B})$ after isolated limb perfusion with buffer alone, $50 \mu \mathrm{g}$ TNF, $40 \mu \mathrm{g}$ melphalan and $40 \mu \mathrm{g}$ melphalan combined with $50 \mu \mathrm{g}$ TNF. Mean ( \pm s.e.m.) of tumour volumes are shown. 
response rate of $70 \%$ (data not shown), conform our experience as published in various extensive series of ILP with melphalan and TNF (Manusama et al, 1996; de Wilt et al, 1999).

\section{Hind limb function and local toxicity}

Shortly after ILP with actinomycin D in combination with TNF severe local toxicity was observed (Table 1). Sham perfusions and perfusions performed with TNF alone resulted in no loss of the limb function. Some toxic side effects were observed in the rats that were perfused with actinomycin $\mathrm{D}$ alone. However, after the addition of TNF to perfusion with actinomycin $\mathrm{D}$ the limb function dramatically deteriorated and strong formation of oedema was observed. After perfusion with melphalan with or without TNF no loss of limb function or oedema formation was observed. Observation of the limb were made just before and 1 day after perfusion with actinomycin D and TNF. Before perfusion the rats showed a tumour in the right hind limb of approximately $1000 \mathrm{~mm}^{3}$. Limb function at this stage was normal and no oedema could be observed. One day after perfusion with actinomycin $\mathrm{D}$ in combination with TNF the rats limb was severely swollen with oedema and the remaining tumour was barely visible. Perfusion with buffer or TNF alone had no effect on formation of oedema, whereas perfusion with actinomycin $\mathrm{D}$ had only a marginal effect.

Tumour tissues as well as healthy tissues (muscle, skin) were examined histopathologically. After sham perfusion some scattered cell necrosis in tumours could be observed, correlating with previous results (Figure 3A). In the muscle tissue from the sham perfused limb, the skeletal muscular fibre and the peripheral nuclei could be observed in a normal pattern. The fibres were intact and no destruction of the tissue was found (Figure 3B). Rats treated with actinomycin $\mathrm{D}$ alone showed massive infiltration of red blood cells and haemorrhagic necrosis in the tumour 1 day after perfusion (Figure 3C). Histological slides taken from the muscle of the limb perfused with only actinomycin $\mathrm{D}$ showed destruction of some of the muscle cells (Figure 3D). One day after perfusion with TNF alone haemorrhagic necrosis in tumour was observed. However the infiltration of red blood cells was not as pronounced as after a perfusion with actinomycin D (Figure 3E). Rats treated with TNF alone showed no damage to the muscle (Figure 3F). Rats treated with a combination actinomycin D and TNF showed again massive infiltration of red blood cells and haemorrhagic necrosis in tumour (Figure 3G). Treatment with a combination of actinomycin $\mathrm{D}$ plus TNF showed massive destruction of the muscle tissue. Cells were torn apart and the nuclei were released in the surrounding muscle tissue (Figure $3 \mathrm{H}$ ).

\section{DISCUSSION}

Previously we have demonstrated that local treatment of advanced tumours with a combination of melphalan and TNF results in high

Table I Limb function and formation of oedema in BN- 175 soft tissue sarcoma bearing rats after isolated limb perfusion with actinomycin D and TNF

\begin{tabular}{lll}
\hline Treatment & Limb function $^{\mathbf{a}}$ & Oedema $^{\mathbf{b}}$ \\
\hline Sham & $2,2,2,2,2$ &,,,,----- \\
$50 \mu \mathrm{g}$ TNF & $2,2,2,2,2$ &,,,,----- \\
$5 \mu \mathrm{g}$ actinomycin D & $2,2,2,2,1$ &,,,,---++ \\
$40 \mu \mathrm{g}$ melphalan & $2,2,2,2,2$ &,,,,----- \\
$5 \mu \mathrm{g}$ actinomycin D and $50 \mu \mathrm{g}$ TNF & $2,2,2,1,0$ &,,,,+++++ \\
$10 \mu \mathrm{g}$ actinomycin D and $50 \mu \mathrm{g}$ TNF & $0,0,0$ &,,+++ \\
$40 \mu \mathrm{g}$ melphalan and $50 \mu \mathrm{g}$ TNF & $2,2,2,2,2$ &,,,,-----
\end{tabular}

a Limb functions were scored as described in Materials and Methods, and graded between 0 and 2. Grade 0: a severe impaired function, grade I: a slightly impaired function, grade 2: an intact function. ${ }^{\mathrm{b}}$ Oedema was scored as no formation of oedema $(-)$, or oedema resulting in leg diameter increase of 1.5-fold or more (+).
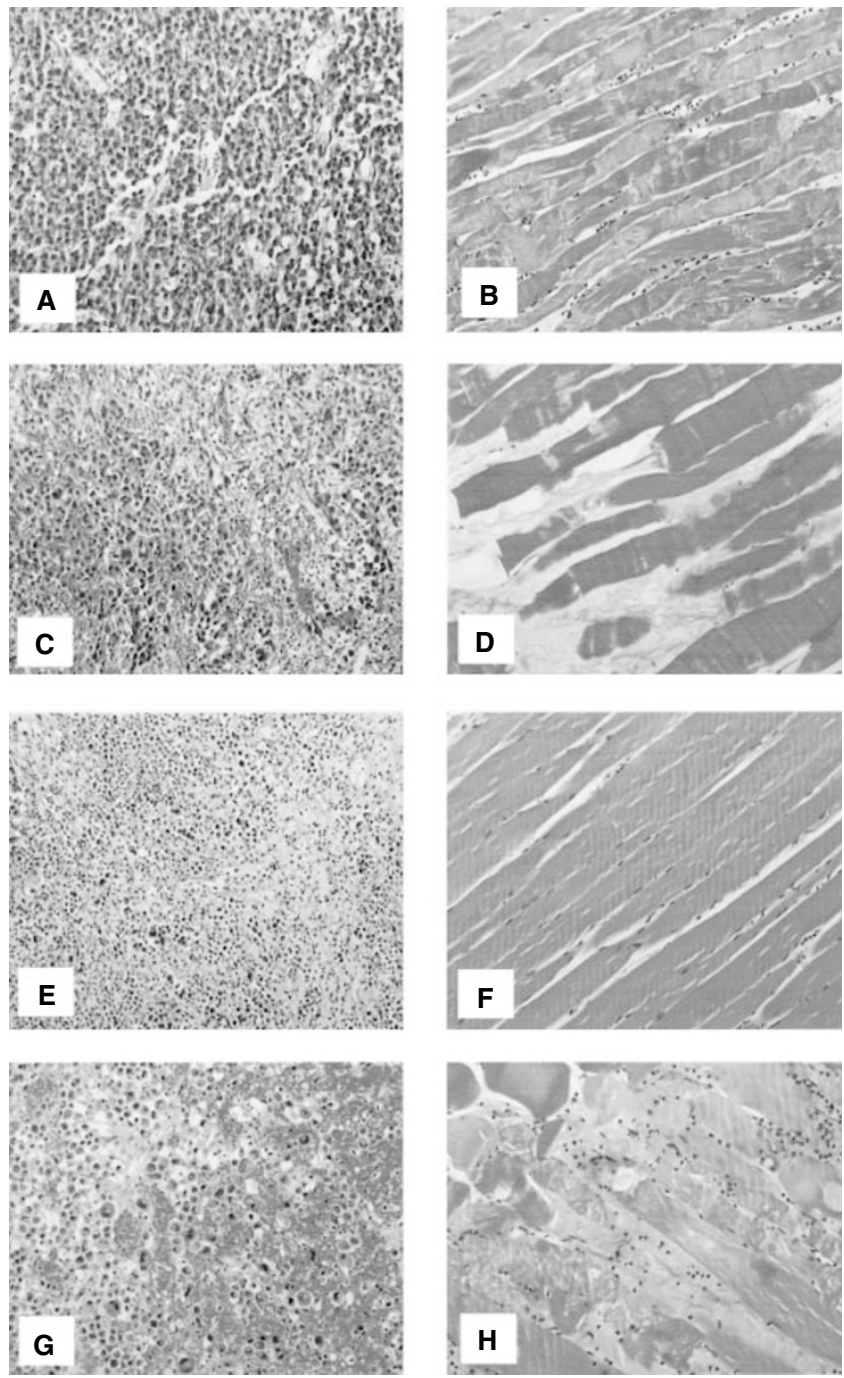

Figure 3 Tissue sections of BN- 175 tumour and muscle, haematoxylin and eosin stained, I day after isolated perfusion (ILP). Histologic overview of BN- I 75 tumour $(\mathbf{A})$ and muscle $(\mathbf{B})$ of the rat limb I day after sham ILP. Histologic sections of tumour tissue $(\mathbf{C})$ and muscle (D) after ILP with actinomycin D, tumour tissue $(\mathbf{E})$ and muscle $(\mathbf{F})$ after ILP with TNF, tumour (G) and muscle $(\mathbf{H})$ after ILP with actinomycin D plus TNF. Original magnification of all sections was $16 x$

response rates. We developed a rat tumour model and showed that results comparable to the clinic can be obtained regarding response rate and type of response (Manusama et al, 1996; de Wilt et al, 1999; Van Der Veen et al, 2000). We used this model to evaluate other drug combinations to improve tumour responses or to diminish toxic side effects. We recently demonstrated that addition of L-NAME to perfusions with melphalan with or without TNF enhanced antitumour effects (de Wilt et al, 2000a). A mutant of TNF, TNF-SAM2, was also investigated in this model and demonstrated similar efficacy as observed with TNF (de Wilt et al, 2000b). In the BN-175 soft tissue sarcoma rat ILP model the usefulness of actinomycin $\mathrm{D}$ was evaluated in correlation to response and toxicity. Actinomycin D is of particular interest both because of its use in the ILP setting in the clinic and because of its interactions with TNF in vitro. Treatment with melphalan in combination with actinomycin D has been reported, but these studies showed no significant difference in response between treatment with the single agent melphalan and the combination therapy (Park et al, 1980). In previous studies with TNF and actinomycin D synergistic effects in 
vitro were seen (Mosende et al, 1977; Aoki et al, 1998). Especially the TNF sensitive tumour cell line WEHI-164 responded in a synergistic fashion to the combination of actinomycin $\mathrm{D}$ and TNF. The soft tissue sarcoma BN-175 used in this study was found to be susceptible to actinomycin D, but addition of TNF did not result in a more cytotoxic effect on these tumour cells. These results correlate with in vitro studies using melphalan or doxorubicin in combination with TNF on several rat tumour cell lines as colon carcinomas and osteosarcomas (van Der Veen et al, 2001). However, in vivo combination of melphalan as well as doxorubicin with TNF did result in strong synergy both in patients and animal models (Lejeune et al, 1995; Eggermont et al, 1996b,c, 1997, 1999; Manusama et al, 1996; Di Filippo et al, 1999; Van Der Veen et al, 2000). We speculated that this is due to the dual targeting of the combination. Whereas the cytotoxic drugs preferentially target tumour cells, TNF mainly affects the tumour associated vasculature, possibly resulting in destruction of the vessels and augmented accumulation of the drugs in the tumour tissue (Eggermont et al, 1997; de Wilt et al, 2000c; ten Hagen et al, 2000; Van Der Veen et al, 2000).

In the present study an isolated limb perfusion with TNF, actinomycin $\mathrm{D}$ or a combination in $\mathrm{BN}-175$ soft tissue sarcoma bearing rats was performed to investigate the tumour response to

\section{REFERENCES}

Alexander RB, Nelson WG, Coffey DS (1987) Synergistic enhancement by tumour necrosis factor of in vitro cytotoxicity from chemotherapeutic drugs targeted at DNA topoisomerase II. Cancer Res 47: 2403-2406

Aoki M, Kuwamura M, Kotani T, Katamoto H, Kubo K, Nomura K, Sasaki $\mathrm{N}$, Ohashi F (1998) In vitro cytotoxicity of recombinant human-TNFalpha and actinomycin D on canine normal and tumour cells. J Vet Med Sci 60: $1087-1091$

Benckhuijsen C, Kroon BB, van Geel AN, Wieberdink J (1988) Regional perfusion treatment with melphalan for melanoma in a limb: an evaluation of drug kinetics. Eur J Surg Oncol 14: 157-163

Buckley NJ, Walther PJ, Das AK, Poulton SH (1989) Schedule-dependent enhanced lethality with combined administration of actinomycin D and tumour necrosis factor in mice. J Biol Response Mod 8: 287-296

Creech O, Krementz ET, Ryan RF, Winblad JN (1958) Chemotherapy of cancer: Regional perfusion utilizing an extracorporeal circuit. Ann Surg 148: $616-632$

de Wilt JH, Manusama ER, van Tiel ST, van Ijken MG, ten Hagen TL, Eggermont AM (1999) Prerequisites for effective isolated limb perfusion using tumour necrosis factor alpha and melphalan in rats. $\mathrm{Br} J$ Cancer $\mathbf{8 0}$ $161-166$

de Wilt JH, Manusama ER, van Etten B, van Tiel ST, Jorna AS, Seynhaeve AL, ten Hagen TL, Eggermont AM (2000a) Nitric oxide synthase inhibition results in synergistic anti-tumour activity with melphalan and tumour necrosis factor alpha-based isolated limb perfusions. $\mathrm{Br} J$ Cancer 83: $1176-1182$

de Wilt JH, Soma G, ten Hagen TL, Kanou J, Takagi K, Nooijen PT, Seynhaevel AL, Eggermont AM (2000b) Synergistic antitumour effect of TNFSAM2 with melphalan and doxorubicin in isolated limb perfusion in rats Anticancer Res 20: 3491 - 3496

de Wilt JH, ten Hagen TL, de Boeck G, van Tiel ST, De Bruijn EA, Eggermont AM (2000c) Tumour necrosis factor alpha increases melphalan concentration in tumour tissue after isolated limb perfusion. Br J Cancer 82: $1000-$ 1003

Di Filippo F, Rossi CR, Vaglini M, Azzarelli A, Anza M, Santinami M, Lise M, Cavaliere F, Giannarelli D, Quagliuolo V, Vecchiato A, Deraco M, Garine R, Foletto M, Botti C, Cavaliere R (1999) Hyperthermic antiblastic perfusion with alpha tumour necrosis factor and doxorubicin for the treatment of soft tissue limb sarcoma in candidates for amputation: results of a phase I study. J Immunother 22: $407-414$

Eggermont A, Schraffordt KH, Klausner JM, Schlag PM, Kroon B, Gustafson B, Steinmann G, Lejeune F (1999) Limb salvage by isolated limb perfusion with tumour necrosis factor alpha and melphalan for locally advanced extremity soft tissue sarcomas: results of 270 perfusions in 246 patients. Proceed ASCO 11: $497-497$ these treatments. We demonstrated that the combination of actinomycin D with TNF was much more effective than ILP with the single agents. However, the response rate was less pronounced compared to previously described perfusions with melphalan or doxorubicin in combination with TNF.

Application of ILP, with leakage below 5\%, allows high local dosages of cytotoxic agents without the systemic side-effects (Benckhuijsen et al, 1988; Buckley et al, 1989; Vrouenraets et al, 1999). This means that local toxicity is the limiting factor. In our study severe toxicity was not observed with actinomycin D or TNF when used as single agents. However, severe toxicity occurred in the rats that underwent an ILP with the combination therapy. This toxicity is only local and consists of permanent loss in limb function and massive oedema formation in the perfused limb.

In conclusion, isolated limb perfusion with actinomycin $\mathrm{D}$ and TNF results in a tumour response of $40 \%$ which is not better than the standard ILP with melphalan plus TNF. Secondly, this therapy was accompanied by dramatic local toxicity, which increased with higher dosages, whereas response rate improved only marginally. Massive destruction of the muscle tissue was observed and as a result a loss of limb function, indicating that isolated limb perfusion with actinomycin D in combination with TNF should not be explored in the clinical setting.

Eggermont AM (1996a) Treatment of melanoma in-transit metastases confined to the limb. Cancer Surv 26: 335-349

Eggermont AM, Schraffordt KH, Klausner JM, Kroon BB, Schlag PM, Lienard D, van Geel AN, Hoekstra HJ, Meller I, Nieweg OE, Kettelhack C, Ben-Ari G, Pector JC, Lejeune FJ (1996b) Isolated limb perfusion with tumour necrosis factor and melphalan for limb salvage in 186 patients with locally advanced soft tissue extremity sarcomas. The cumulative multicenter European experience. Ann Surg 224: 756-764

Eggermont AM, Schraffordt KH, Klausner JM, Lienard D, Kroon BB, Schlag PM, Ben-Ari G, Lejeune FJ (1997) Isolation limb perfusion with tumour necrosis factor alpha and chemotherapy for advanced extremity soft tissue sarcomas. Semin Oncol 24: $547-555$

Eggermont AM, Schraffordt KH, Lienard D, Kroon BB, van Geel AN, Hoekstra HJ, Lejeune FJ (1996c) Isolated limb perfusion with high-dose tumour necrosis factor-alpha in combination with interferon-gamma and melphalan for nonresectable extremity soft tissue sarcomas: a multicenter trial. $J$ Clin Oncol 14: $2653-2665$

Lasek W, Giermasz A, Kuc K, Wankowicz A, Feleszko W, Golab J, Zagozdzon R, Stoklosa T, Jakobisiak M (1996) Potentiation of the anti-tumour effect of actinomycin $\mathrm{D}$ by tumour necrosis factor alpha in mice: correlation between in vitro and in vivo results. Int J Cancer 66: 374-379

Lejeune F, Lienard D, Eggermont A, Schraffordt KH, Rosenkaimer F, Gerain J, Klaase J, Kroon B, Vanderveken J, Schmitz P (1995) Administration of high-dose tumour necrosis factor alpha by isolation perfusion of the limbs. Rationale and results. J Infus Chemother 5: 73-81

Lienard D, Ewalenko P, Delmotte JJ, Renard N, Lejeune FJ (1992) High-dose recombinant tumour necrosis factor alpha in combination with interferon gamma and melphalan in isolation perfusion of the limbs for melanoma and sarcoma. J Clin Oncol 10: $52-60$

Manusama ER, Nooijen PT, Stavast J, Durante NM, Marquet RL, Eggermont AM (1996) Synergistic antitumour effect of recombinant human tumour necrosis factor alpha with melphalan in isolated limb perfusion in the rat. $B r J$ Surg 83: $551-555$

Mosende C, Gutierrez M, Caparros B, Rosen G (1977) Combination chemotherapy with bleomycin, cyclophosphamide and dactinomycin for the treatment of osteogenic sarcoma. Cancer 40: 2779-2786

Park RC, Blom J, Disaia PJ, Lagasse LD, Blessing JA (1980) Treatment of women with disseminated or recurrent advanced ovarian cancer with melphalan alone in combination with 5-fluorouracil and dactinomycin or with the combination of cytoxan, 5-fluorouracil and dactinomycin. Cancer 45: $2529-2542$

Skehan P, Storeng R, Scudiero D, Monks A, McMahon J, Vistica D, Warren JT, Bokesch H, Kenney S, Boyd MR (1990) New colorimetric cytotoxicity assay for anticancer-drug screening. J Natl Cancer Inst 82: 1107-1112 
ten Hagen TL, Van DV, Nooijen PT, van Tiel ST, Seynhaeve AL, Eggermont AM (2000) Low-dose tumour necrosis factor-alpha augments antitumor activity of stealth liposomal doxorubicin (DOXIL) in soft tissue sarcoma-bearing rats. Int J Cancer 87: 829-837

UKCCCR (1998) United Kingdom Co-ordinating Committee on Cancer Research (UKCCCR) Guidelines for the Welfare of Animals in Experimental Neoplasia. (Second Edition) Br J Cancer 77: 1-10

Van Der Veen AH, de Wilt JH, Eggermont AM, van Tiel ST, Seynhaeve AL, ten Hagen TL (2000) TNF-alpha augments intratumoural concentrations of doxorubicin in TNF-alpha-based isolated limb perfusion in rat sarcoma models and enhances anti-tumour effects. Br J Cancer 82: 973-980
Van Der Veen AH, ten Hagen TL, Seynhaeve AL, Eggermont A (2002) Lack of cell cycle specific effects of tumour necrosis factor alpha on tumour cells in vitro: implication tumour therapy with doxorubicin. Cancer invest 20: in press

Vrouenraets BC, Kroon BB, Ogilvie AC, van Geel AN, Nieweg OE, Swaak AJ, Eggermont AM (1999) Absence of severe systemic toxicity after leakagecontrolled isolated limb perfusion with tumour necrosis factor-alpha and melphalan. Ann Surg Oncol 6: 405-412 